\title{
Changes in Extreme Climate Indices for the Northeastern United States, 1870-2005
}

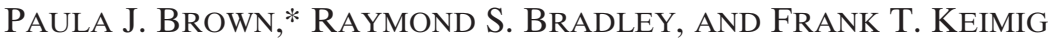 \\ Climate System Research Center, Department of Geosciences, University of Massachusetts, Amherst, Massachusetts
}

(Manuscript received 31 July 2009, in final form 17 June 2010)

\begin{abstract}
The northeastern United States is one of the most variable climates in the world, and how climate extremes are changing is critical to populations, industries, and the environment in this region. A long-term (1870-2005) temperature and precipitation dataset was compiled for the northeastern United States to assess how the climate has changed. Adjustments were made to daily temperatures to account for changes in mean, variance, and skewness resulting from inhomogeneities, but precipitation data were not adjusted. Trends in 17 temperature and 10 precipitation indices at 40 stations were evaluated over three time periods-1893-2005, 18931950, and 1951-2005-and over 1870-2005 for a subset of longer-term stations. Temperature indices indicate strong warming with increases in the frequency of warm events (e.g., warm nights and warm summer days) and decreases in the frequency of cold events (e.g., ice days, frost days, and the cold spell duration indicator). The strongest warming is exhibited in the decrease in frost days and the increase in growing season length. Although maximum temperatures indices showed strong warming trends over the period 1893-1950, subsequent trends show little change and cooling. Few significant trends were present in the precipitation indices; however, they displayed a tendency toward wetter conditions. A stepwise multiple linear regression analysis indicated that some of the variability in the 27 indices from 1951 to 2002 was explained by the North Atlantic Oscillation, Pacific decadal oscillation, and Pacific-North American pattern. However, teleconnection patterns showed little influence on the 27 indices over a 103 -yr period.
\end{abstract}

\section{Introduction}

Climate change research commonly focuses on longterm monthly or seasonal averages, such as gridded global temperature (Brohan et al. 2006; Hansen et al. 2001; Smith and Reynolds 2005) and precipitation datasets (Mitchell and Jones 2005; Vose et al. 1992). These datasets do not provide data at a sufficient resolution to elucidate how extreme events are affected by climatic variability. However, the recent digitization and availability of higher-resolution daily records has enabled a growing number of studies to focus on the changes in climate extremes. The impact of climate change is perceptibly greater when it is associated with extreme events, especially where vulnerable populations or highvalue properties (such as in the northeastern United States) are at risk (Trenberth et al. 2007).

* Current affiliation: Cornell University, Ithaca, New York.

Corresponding author address: Paula Brown, Dept. of Earth and Atmospheric Science, 1121 Bradfield Hall, Cornell University, Ithaca, NY 14853.

E-mail:pjb238@cornell.edu
International collaborations enabled the dissemination of a number of restricted datasets through extreme climate indices to a number of both regional and global-scale studies (Klein Tank et al. 2006; Zhang et al. 2005; Manton et al. 2001; Frich et al. 2002; Alexander et al. 2006; Peterson et al. 2008). For example, Alexander et al. (2006) noted a tendency toward wetter conditions over the twentieth century and significant warming, in Eurasia, North America, and parts of Australia. Warming over the 1979-2003 period was driven by a shift in the tails of the temperature distribution toward higher maximum temperatures, and (especially) minimum temperatures (Alexander et al. 2006). Della-Marta et al. (2007) have also shown that western European heat waves have doubled in length and increased in frequency since 1880 . These are attributed to significant increases in both the mean and variability of maximum summer temperatures (Della-Marta et al. 2007). Similar warming has been seen globally, with increases in warm temperature extremes and decreases in cold temperature extremes since 1870 (Horton et al. 2001). However, a more recent global study by Alexander et al. (2006) showed an asymmetric temperature shift associated with greater warming in minimum temperatures than maximum temperatures and 
precipitation changes toward wetter conditions. There have also been increases in the growing season length, an increase in the number of frost-free days, and a decrease in the number of cold nights globally (Alexander et al. 2006).

A recent study of climate extremes using an unhomogenized dataset from the northeastern United States by Griffiths and Bradley (2007) concurred with these numerous studies, showing that the frequency of higher temperatures had increased, particularly over the last few decades. Warming resulted in longer growing seasons, where increases of up to 2.2 days decade ${ }^{-1}$ over the period 1926-2000 were noted. Frost days showed increasing and decreasing trends during the 1926-60 and 1960-2000 periods, respectively. Based on GCM simulations for North America, Meehl et al. (2004) predicted increases in frost days and a lengthening growing season in the future and little future change in frost days for eastern North America due to a shift in winter cold air from Canada.

Most studies of climate extremes are limited to the last $\sim 50$ years or less, simply because longer-term daily datasets have not been commonly digitized. Furthermore, where long-term data are available, uncertainties about their homogeneity limit their use in studies of extremes. The northeastern United States has many of the longest daily climatological records in the United States, and over recent years the digitization of these records has been prioritized through the Climate Data Modernization Program (CDMP) of the NOAA/National Climatic Data Center. Through this effort, digitized datasets extending back to the nineteenth century are now available, which enable contemporary trends in climate extremes to be placed in a longer historical context.

However, so as to fully utilize this new data, inhomogeneities such as station moves, urbanization, and observation/instrument changes that have affected observations and distorted underlying trends in the series must be accounted for. Here, we focus on assessing the quality of climate records in the northeastern United States and making adjustments for inhomogeneities wherever possible. The resultant dataset can then be used to assess long-term changes in daily climate extremes with confidence in the trends and statistics obtained from them. Associations between variability in climate indices and large-scale circulation patterns are also explored. Although the northeastern United States is a well-studied region, the availability of newly digitized historical data and a homogeneous dataset are critical to understanding long-term trends and variability in the climate record.

\section{Methods}

Daily temperature and precipitation data from the United States Historical Climatology Network (USHCN)

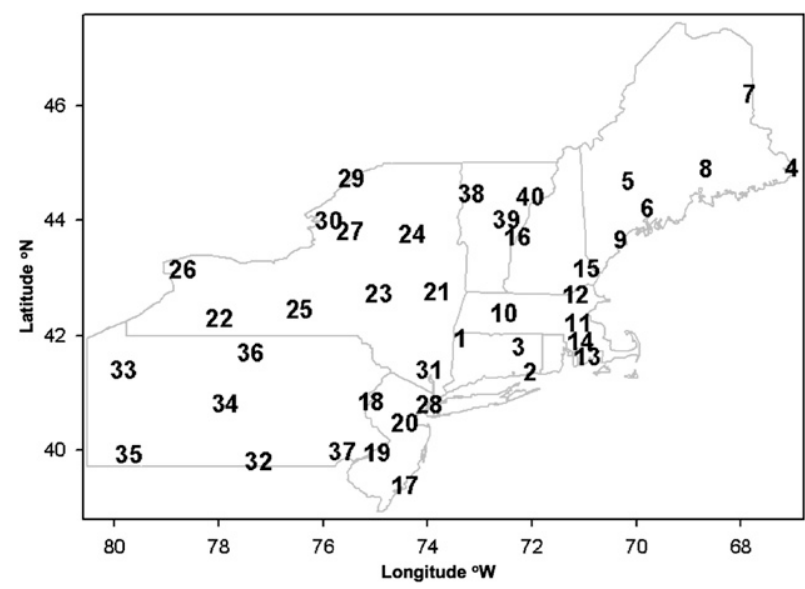

FIG. 1. Meteorological stations from the Northeast used for this study and enumerated according to Table 1.

(Easterling et al. 1999), the National Weather Service Cooperative Observers Network (COOP), and CDMP eighteenth- and nineteenth-century Forts datasets were utilized. Figure 1 shows the 40 stations selected in the northeastern United States, with the length of record listed in Table 1. Stations with observations dating from the 1800s were chosen based on the selection criteria used by Alexander et al. (2006): data had to be at least $80 \%$ complete and end no earlier than 1999. However, some exceptions were made to ensure broad geographical distribution and exceptional length of record when appropriate (Table 1). USHCN data formed the basis of the dataset; where necessary these were supplemented by COOP and Forts data. Quality control procedures have previously been applied to the USHCN data (Williams et al. 2006); therefore, these data were only checked for gross errors and outliers that exceeded four standard deviations from the mean for each day, using the quality control procedures of the Microsoft Excel-based RClimDex software (Zhang and Yang 2006).

More comprehensive quality control was performed on the COOP data, as independently digitized raw monthly records were available to check daily temperature and precipitation records. Discrepancies between the monthly data and monthly data derived from the daily records were validated with original documents to detect digitization errors for the 30 stations listed in Table 2. More errors were found in the older temperature observations (Fig. 2) as these older documents were often of poor quality or the handwriting was difficult to read. The corrections made to precipitation records are distorted owing to the prevalence of a large number of "missing values" instead of zeros when no rainfall was recorded. In total $93 \%$ of the corrections made to precipitation data were to substitute a zero for a previously recorded as "missing" value. 
TABLE 1. Northeastern U.S. stations' temperature start dates (Tstart), precipitation start dates (Pstart), end dates (End), and years temperature break points were detected.

\begin{tabular}{|c|c|c|c|c|c|}
\hline & Station & Tstart & Pstart & End & Temperature break points \\
\hline 1 & Falls Village/Cream Hill, CT & 1896 & 1893 & 2005 & 1916 \\
\hline 2 & Groton/New London, CT & 1877 & 1871 & 2005 & $1985 ; 1955 ; 1951 ; 1940 ; 1892$ \\
\hline 3 & Storrs, CT & 1888 & 1888 & 2005 & $1968 ; 1961 ; 1942 ; 1921$ \\
\hline 4 & Eastport, ME & 1873 & 1873 & 2005 & 1953 \\
\hline 5 & Farmington, ME & 1893 & 1893 & 2005 & $1966 ; 1945 ; 1942 ; 1898$ \\
\hline 6 & Gardiner, ME & 1870 & 1870 & 2005 & 1985; 1906; 1890; 1884 \\
\hline 7 & Houlton, ME & 1893 & 1893 & 2005 & $1985 ; 1972 ; 1902$ \\
\hline 8 & Orono, ME & 1870 & 1870 & 2005 & $1961 ; 1892$ \\
\hline 9 & Portland, ME & 1874 & 1872 & 2005 & $1940 ; 1884$ \\
\hline 10 & Amherst, MA & 1884 & 1870 & 2005 & $1991 ; 1979 ; 1966 ; 1961 ; 1902$ \\
\hline 11 & Blue Hll/Boston, MA & 1877 & 1871 & 2005 & 1892 \\
\hline 12 & Lawrence, MA & 1893 & 1893 & 2005 & 1988; 1967; 1929 \\
\hline 13 & New Bedford, MA & 1893 & 1870 & 2002 & $1985 ; 1974 ; 1905$ \\
\hline 14 & Taunton, MA & 1883 & 1883 & 2005 & $1986 ; 1962 ; 1930 ; 1926 ; 1920 ; 1895 ; 1885$ \\
\hline 15 & Durham, NH & 1893 & 1893 & 2005 & $1992 ; 1986 ; 1975 ; 1959 ; 1943 ; 1927$ \\
\hline 16 & Hanover, NH & 1893 & 1884 & 2005 & $1990 ; 1897$ \\
\hline 17 & Atlantic City, NJ & 1874 & 1874 & 2005 & - \\
\hline 18 & Belvidere, NJ & 1893 & 1893 & 2005 & $1981 ; 1963 ; 1959 ; 1923$ \\
\hline 19 & Moorestown/Philadelphia, NJ & 1870 & 1870 & 2005 & $1973 ; 1928 ; 1892$ \\
\hline 20 & New Brunswick, NJ & 1893 & 1893 & 2005 & $1978 ; 1968$ \\
\hline 21 & Albany, NY & 1874 & 1874 & 2005 & $1985 ; 1965 ; 1938 ; 1884 ; 1880$ \\
\hline 22 & Angelica, NY & 1893 & 1893 & 2005 & $1971 ; 1917$ \\
\hline 23 & Cooperstown, NY & 1890 & 1870 & 2005 & $1948 ; 1942$ \\
\hline 24 & Indian Lake, NY & 1899 & 1899 & 2005 & $1925 ; 1904$ \\
\hline 25 & Ithaca, NY & 1893 & 1893 & 2005 & $1969 ; 1943$ \\
\hline 26 & Lockport, NY & 1893 & 1893 & 1999 & 1905 \\
\hline 27 & Lowville, NY & 1891 & 1891 & 2005 & 1980; 1917; 1912 \\
\hline 28 & New York City, NY & 1870 & 1870 & 2005 & $1960 ; 1876 ; 1854$ \\
\hline 29 & Ogdensburg, NY & 1893 & 1893 & 2005 & $1983 ; 1970 ; 1961$ \\
\hline 30 & Watertown, NY & 1893 & 1893 & 2005 & $1946 ; 1926 ; 1913$ \\
\hline 31 & West Point, NY & 1870 & 1870 & 2005 & $1946 ; 1927 ; 1900$ \\
\hline 32 & Gettysburg/Germantown, PA & 1883 & 1884 & 2005 & $1947 ; 1927 ; 1892$ \\
\hline 33 & Franklin, PA & 1897 & 1870 & 2005 & $1965 ; 1952 ; 1936$ \\
\hline 34 & State College, PA & 1893 & 1893 & 2005 & $1969 ; 1940$ \\
\hline 35 & Uniontown, PA & 1894 & 1894 & 2005 & $1985 ; 1970$ \\
\hline 36 & Wellsboro, PA & 1893 & 1893 & 2005 & $1999 ; 1966 ; 1950 ; 1914$ \\
\hline 37 & West Chester, PA & 1893 & 1893 & 2005 & 1936 \\
\hline 38 & Burlington, VT & 1877 & 1870 & 2005 & $1973 ; 1959 ; 1943 ; 1906$ \\
\hline 39 & Chelsea/Strafford, VT & 1884 & 1873 & 2005 & $2000 ; 1978 ; 1964 ; 1949 ; 1941 ; 1892$ \\
\hline 40 & Saint Johnsbury, VT & 1894 & 1894 & 2005 & - \\
\hline
\end{tabular}

The magnitude of the corrections made to both temperature and precipitation data were generally small, but large discrepancies were also evident in many cases, as shown Fig. 2. A bimodal distribution seen in the temperature corrections is due to the frequent misreading of numbers, for example, mistaking 3 and 8 or 1 and 7 . The range of individual daily temperature corrections is $\pm 27.8^{\circ} \mathrm{C}\left( \pm 50^{\circ} \mathrm{F}\right)$ and precipitation corrections range from $115.6 \mathrm{~mm}$ to $-141.2 \mathrm{~mm}$.

To assess the effect of digitization errors on temperature and precipitation, climate indices derived from Franklin, Pennsylvania, data were selected, as it was the station with the most temperature corrections as well as requiring over 860 precipitation corrections. A nonparametric
Mann-Whitney test was performed on the changes in mean and trend between the uncorrected and corrected data for seven climate indicators from 1897 to 1925 . The indices tested were frost days, growing season length, highest temperatures, lowest temperatures, number of heavy precipitation days over $20 \mathrm{~mm}$, and annual precipitation. No significant differences were found between the mean or trend in any of the indices for Franklin. However, the number of years when there was sufficient data to generate the precipitation indices almost doubled from 16 to $29 \mathrm{yr}$, with only 2 of the first $11 \mathrm{yr}$ of data originally containing enough data to derive annual indices for precipitation. The completeness of precipitation data is greatly improved in this dataset compared to the 
TABLE 2. Total number of corrections made for digitization errors in daily minimum temperature (Min), maximum temperature (Max), and precipitation (Precip) observations during the time periods specified.

\begin{tabular}{|c|c|c|c|c|c|c|}
\hline State & COOP station name & Start date & End date & Min & Max & Precip \\
\hline $\mathrm{CT}$ & Falls Village & $1 / 1916$ & $5 / 1948$ & 64 & 39 & 1305 \\
\hline $\mathrm{CT}$ & Groton/New London & $1 / 1895$ & $12 / 2002$ & 121 & 108 & 913 \\
\hline ME & Farmington & $1 / 1893$ & $12 / 1925$ & 222 & 206 & 531 \\
\hline ME & Gardiner & $1 / 1885$ & $5 / 1948$ & 217 & 104 & 1949 \\
\hline ME & Houlton $5 \mathrm{~N} /$ Houlton & $1 / 1893$ & $12 / 2005$ & 466 & 450 & 363 \\
\hline $\mathrm{ME}$ & Orono & $1 / 1893$ & $5 / 1948$ & 97 & 119 & 1298 \\
\hline MA & Amherst & $1 / 1893$ & $12 / 1925$ & 133 & 104 & 414 \\
\hline MA & Lawrence & $1 / 1893$ & $12 / 1925$ & 82 & 33 & 876 \\
\hline MA & New Bedford & $1 / 1893$ & $5 / 1948$ & 156 & 232 & 2676 \\
\hline MA & Taunton & $1 / 1893$ & $5 / 1948$ & 178 & 153 & 1187 \\
\hline $\mathrm{NH}$ & Durham & $1 / 1893$ & 12/1949 & 183 & 179 & 5533 \\
\hline $\mathrm{NH}$ & Hanover & $1 / 1884$ & $12 / 1935$ & 15 & 15 & 1082 \\
\hline NJ & Belvidere & $1 / 1893$ & $12 / 1929$ & 14 & 34 & 419 \\
\hline NJ & Moorestown & $1 / 1893$ & $12 / 1925$ & 165 & 142 & 1179 \\
\hline NY & Angelica & $1 / 1893$ & $12 / 1925$ & 57 & 45 & 228 \\
\hline NY & Indian Lake 2SW & $1 / 1899$ & $5 / 1948$ & 42 & 180 & 409 \\
\hline NY & Ithaca Cornell University & $1 / 1893$ & $12 / 2002$ & 8 & 45 & 45 \\
\hline NY & Lockport $3 \mathrm{~S}$ & $1 / 1893$ & $12 / 1925$ & 53 & 93 & 280 \\
\hline NY & Lowville & $1 / 1891$ & $12 / 1925$ & 0 & 52 & 546 \\
\hline NY & Ogdensburg $4 \mathrm{Ne}$ & $1 / 1893$ & $12 / 1925$ & 2 & 25 & 1289 \\
\hline NY & Watertown & $1 / 1893$ & $12 / 1925$ & 10 & 4 & 296 \\
\hline NY & West Point & $1 / 1890$ & $5 / 1948$ & 14 & 30 & 3290 \\
\hline PA & Eisenhower National History Site/Gettysburg & $1 / 1893$ & $12 / 2005$ & 5 & 128 & 137 \\
\hline PA & Franklin & $1 / 1897$ & $12 / 1925$ & 561 & 575 & 862 \\
\hline PA & State College & $1 / 1893$ & $12 / 1925$ & 95 & 127 & 513 \\
\hline PA & Uniontown $1 \mathrm{Ne}$ & $1 / 1894$ & $12 / 1925$ & 175 & 182 & 1027 \\
\hline PA & Wellsboro 4 Sw/Wellsboro & $1 / 1893$ & $12 / 2005$ & 73 & 67 & 784 \\
\hline PA & West Chester 2 NW & $1 / 1893$ & $5 / 1948$ & 212 & 236 & 868 \\
\hline VT & Chelsea & $1 / 1893$ & $5 / 1948$ & 310 & 338 & 484 \\
\hline VT & Saint Johnsbury Fairbanks Museum & $1 / 1894$ & $12 / 1925$ & 45 & 38 & 6 \\
\hline
\end{tabular}

original COOP station data, despite the nonsignificant change in mean and trend. Therefore, the effect of digitization errors present in the COOP data is negligible with respect to both mean and extreme temperature indicators, but it greatly improves the quality (by correcting errors) and duration of precipitation indices.

Precipitation data were not adjusted because of the complexities involved in homogenizing precipitation data and the lack of reliable methods to adjust daily precipitation. Quality-controlled temperature data were assessed for inhomogeneities by detecting statistically significant breaks (relative to a reference series created from nearby stations) and then adjusting the data to account for the shift in temperatures. Sets of reference series were created for each station from surrounding stations within a $161-\mathrm{km}$ radius and then weighted on correlation $(r)$ and distance measures, based on the method used by Trewin (2001). Only reference stations with Pearson correlation coefficients over 0.6 were used to create the reference series to eliminate those with distinctly different climates. The distance (in degrees) between the station and a reference station and the weighting $w$ are calculated according to the following:

$$
\begin{aligned}
d^{2}= & (\text { latitudinal distance from station })^{2} \\
& +(\text { longitudinal distance from station })^{2}
\end{aligned}
$$

and

$$
w=[r \times(101-d)]^{2} \quad r>0.6, \quad d<101 .
$$

A two-phase regression procedure, named the RHtest version 1 (Wang and Feng 2004), was then applied to monthly data to determine where possible inhomogeneities occurred. The RHtest is constantly being improved, and the most up-to-date version available at that time was used. Potential inhomogeneities were identified using monthly and annual time series and, where "changepoints" were detected in four or more months of a year, a potential inhomogeneity was identified. A four-month threshold was determined by investigating the results from a few stations to establish a cutoff between coincidental 

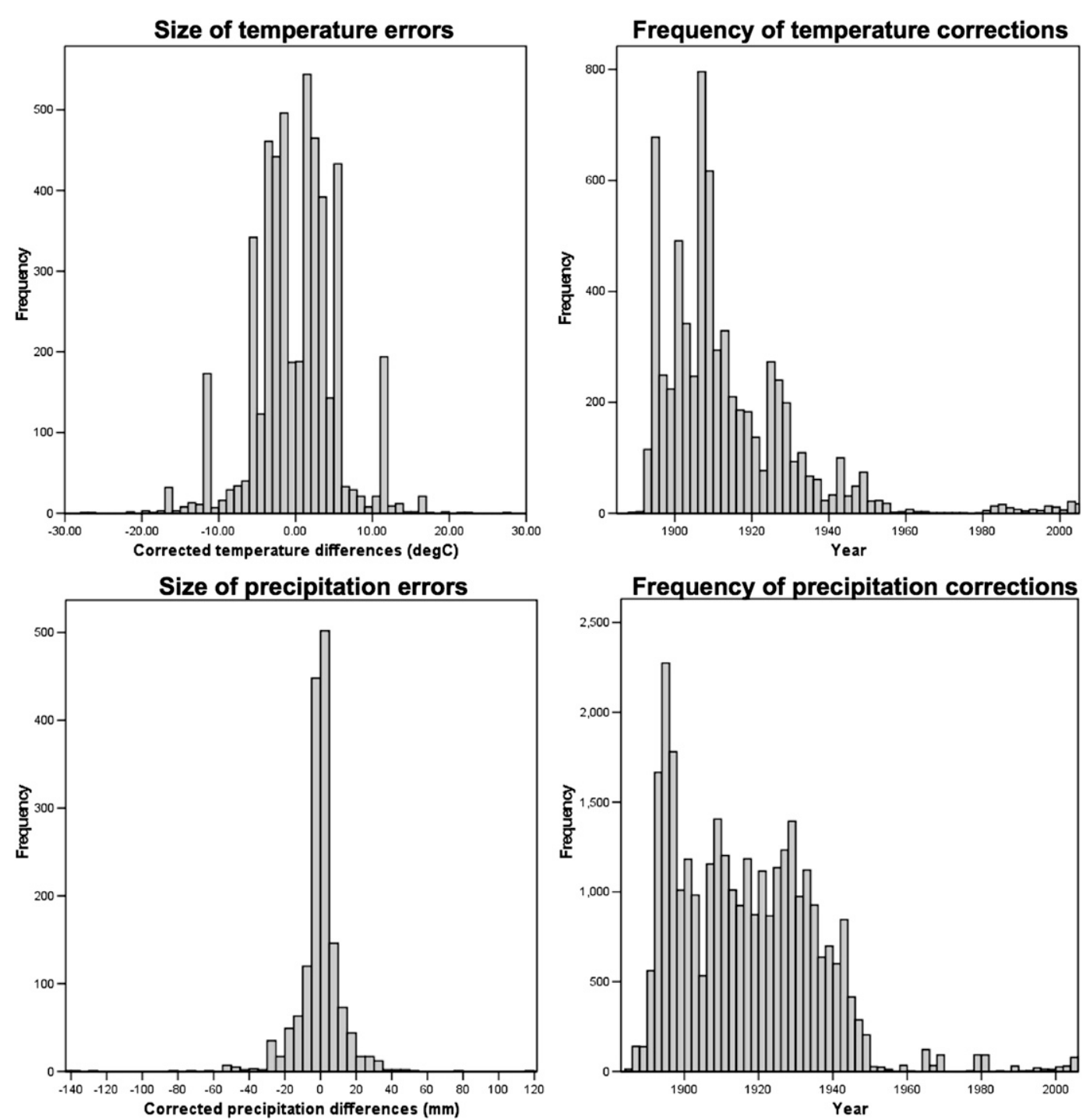

FIG. 2. Differences between the original data and corrected data (and the frequency of corrections per year) for temperature and precipitation.

breakpoint occurrences and genuine detectable breaks that are associated with temperature shifts. These inhomogeneities were then verified with station changes identified in metadata from the USCHN monthly station histories (Menne et al. 2006) before temperatures were adjusted. Visual inspections of each minimum and maximum temperature series with neighbor stations were also performed to ensure no large inhomogeneities were missed. On average three inhomogeneities per station were detected. Taunton, Massachusetts, contained the most break points with seven inhomogeneities in its temperature record.

Daily temperature adjustments were made using the method of Della-Marta and Wanner (see Della-Marta and Wanner 2006 for details), which adjusts temperatures based on the shift in temperature distribution before and after a break point/inhomogeneity, relative to a highly correlated neighbor station. This method is suited to the analysis of extremes, as temperatures are not simply adjusted for a shift in the mean; it also models the effect of the shift on the higher order moments of the frequency distribution. The most highly correlated neighbor station with no inhomogeneities during the same period of time was chosen for the adjustment. Adjustments were made based on a 10-yr "window" (5 years before and after the inhomogeneity) whenever possible, with a window period of $2 \mathrm{yr}$ considered the minimum viable window to provide an adjustment. A visual examination of the relationship between the candidate and neighbor stations for the window period surrounding the inhomogeneity was also performed to ensure that a consistent relationship existed. 
TABLE 3. List of the 27 ETCCDI core climate indices and their definitions (available online at http://cccma.seos.uvic.ca/ETCCDI/ list_27_indices.shtml).

\begin{tabular}{|c|c|c|c|}
\hline ID & Indicator name & Definitions & Units \\
\hline SU25 & Summer days & Annual count when TX (daily maximum) $>25^{\circ} \mathrm{C}$ & Days \\
\hline ID0 & Ice days & Annual count when $\mathrm{TX}$ (daily maximum) $<0^{\circ} \mathrm{C}$ & Days \\
\hline TR20 & Tropical nights & Annual count when TN (daily minimum) $>20^{\circ} \mathrm{C}$ & Days \\
\hline FD0 & Frost days & Annual count when $\mathrm{TN}$ (daily minimum) $<0^{\circ} \mathrm{C}$ & Days \\
\hline TXx & Max Tmax & Annual maximum value of daily maximum temp & ${ }^{\circ} \mathrm{C}$ \\
\hline TXn & Min Tmax & Annual minimum value of daily maximum temp & ${ }^{\circ} \mathrm{C}$ \\
\hline TNx & Max Tmin & Annual maximum value of daily minimum temp & ${ }^{\circ} \mathrm{C}$ \\
\hline $\mathrm{TNn}$ & Min Tmin & Annual minimum value of daily minimum temp & ${ }^{\circ} \mathrm{C}$ \\
\hline TX90p & Warm days & Percentage of days when $\mathrm{TX}>90$ th percentile & $\%$ \\
\hline TX10p & Cool days & Percentage of days when TX $<10$ th percentile & $\%$ \\
\hline TN10p & Cool nights & Percentage of days when $\mathrm{TN}<10$ th percentile & $\%$ \\
\hline TN90p & Warm nights & Percentage of days when TN $>90$ th percentile & $\%$ \\
\hline GSL & Growing season length & $\begin{array}{l}\text { Annual }(1 \mathrm{Jan}-31 \mathrm{Dec} \text { in } \mathrm{NH}) \text { count between first span of at } \\
\text { least } 6 \text { days with } \mathrm{TG}>5^{\circ} \mathrm{C} \text { and first span after } 1 \text { July } \\
\text { of } 6 \text { days with } \mathrm{TG}<5^{\circ} \mathrm{C}\end{array}$ & Days \\
\hline DTR & Diurnal temperature range & Annual mean difference between TX and TN & ${ }^{\circ} \mathrm{C}$ \\
\hline WSDI & Warm spell duration indicator & $\begin{array}{l}\text { Annual count of days with at least } 6 \text { consecutive days when } \\
\text { TX }>90 \text { th percentile }\end{array}$ & Days \\
\hline CSDI & Cold spell duration indicator & $\begin{array}{l}\text { Annual count of days with at least } 6 \text { consecutive days when } \\
\text { TN }<10 \text { th percentile }\end{array}$ & Days \\
\hline RX1day & Max 1-day precipitation amount & Annual maximum 1-day precipitation & $\mathrm{mm}$ \\
\hline RX5day & Max 5-day precipitation amount & Annual maximum consecutive 5-day precipitation & $\mathrm{mm}$ \\
\hline SDII & Simple daily intensity index & $\begin{array}{l}\text { Annual total precipitation divided by the number of wet } \\
\text { days (defined as PRCP }>=1.0 \mathrm{~mm} \text { ) in the year }\end{array}$ & $m m$ day $^{-1}$ \\
\hline $\mathrm{R} 10$ & Number of heavy precipitation days & Annual count of days when PRCP $>=10 \mathrm{~mm}$ & Days \\
\hline $\mathrm{R} 20$ & Number of very heavy precipitation days & Annual count of days when PRCP $>=20 \mathrm{~mm}$ & Days \\
\hline $\mathrm{R} 25$ & Number of days above $25 \mathrm{~mm}$ & $\begin{array}{l}\text { Annual count of days when } \mathrm{PRCP} \geq 25 \mathrm{~mm}, 25 \text { is } \\
\text { user-defined threshold }\end{array}$ & Days \\
\hline CDD & Consecutive dry days & Maximum number of consecutive days with $\mathrm{RR}<1 \mathrm{~mm}$ & Days \\
\hline CWD & Consecutive wet days & Maximum number of consecutive days with $\mathrm{RR} \geq 1 \mathrm{~mm}$ & Days \\
\hline R95p & Very wet days & Annual total PRCP when RR > 95th percentile & $\mathrm{mm}$ \\
\hline R99p & Extremely wet days & Annual total PRCP when RR $>$ 99th percentile & $\mathrm{mm}$ \\
\hline PRCPTOT & Annual total wet-day precipitation & Annual total PRCP in wet days $(\mathrm{RR} \geq 1 \mathrm{~mm})$ & $\mathrm{mm}$ \\
\hline
\end{tabular}

The adjusted data were then used to develop climate extreme indices for analysis. The joint World Meteorological Organization Commission on Climatology $(\mathrm{CCl})$ and the Climate Variability and Prediction (CLIVAR) Expert Team on Climate Change Detection and Indices (ETCCDI) has worked to produce climate indices and software to aid collaborative international research (Karl et al. 1999; Peterson et al. 2001). A core set of 27 indices (Table 3) has been developed by the ETCCDI to standardize the definitions and analysis of extremes (Klein Tank et al. 2009), and these were used to investigate climate change in the northeastern United States. Improvements have been made to the indices over recent years (Peterson et al. 2008), and these have been incorporated into the RClimDex software used to calculate the indices. Many of the indices, such as frost days, ice days, growing season length, and extreme wet days, are important for agriculture and local infrastructure in the Northeast. Zhang et al. (2009) also noted a problem due to the resolution of temperature data creating some bias in the percentile indices; however, the resultant loss of precision does not affect the accuracy of the indices.

Trends in the climate indices were calculated over a number of different time intervals to estimate the changes over time from 1893 to 2005. Subperiods of approximately 27 -yr periods were also chosen to assess changes in trends using similar time scales to those used by Alexander et al. (2006) in their long-term global climate indices study. Little difference in trend estimators exists between ordinary least squares (OLS) and nonparametric methods (Moberg and Jones 2005; Cohn and Lins 2005); the OLS method was chosen here. However, it should be noted that, despite its accepted use (Griffiths and Bradley 2007), the OLS method is sensitive to outliers and non-Gaussian distributions that may be present. The field significance of these trends was determined based on the method of Kiktev et al. (2003), which uses a moving-block bootstrap resampling technique (Wilks 1997) to account for autocorrelation in the data. By generating 1000 new fields randomly from the original dataset, using a block size of 

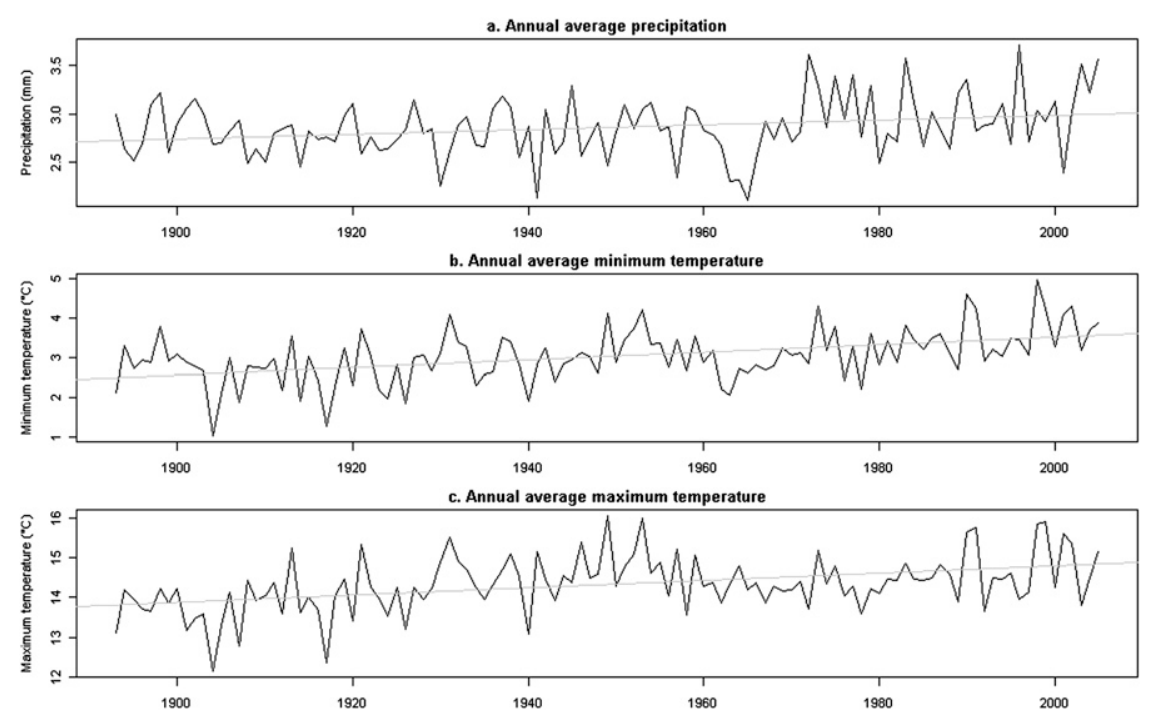

FIG. 3. Annual average (a) precipitation, (b) minimum temperature, and (c) maximum temperature for northeastern U.S. stations (1893-2005); linear trends shown in gray.

$2 \mathrm{yr}$, the trend was able to be assessed for significance utilizing the data's natural variability. The block size of 2 yr was the same as that used by Alexander et al. (2006) and Griffiths and Bradley (2007). Significance was then determined where trends exceeded the $2.5 \%$ and $97.5 \%$ percentiles to create a $95 \%$ confidence interval.

\section{Results}

In this section, we present the regional trends in temperature and precipitation and their derived indices. An increase in annual average precipitation, minimum temperature, and maximum temperature has occurred since 1893 (Fig. 3). However, the increase in precipitation can be attributed to an upward shift that occurred in the 1970s that is present in other northeastern datasets (Keim and Rock 2002). Precipitation amounts show daily precipitation to be increasing in frequency and intensity (Fig. 4), and seasonal precipitation changes reflected the same trends.

The seasonal changes in the minimum and maximum temperature distributions over four time periods between 1893 and 2005 also reflect warming (Figs. 5 and 6). However, warming has not occurred consistently for maximum temperatures that increase from 1893 until the 1950s, after which little long-term change has occurred. Maximum temperature changes are also dominated by a general distributional shift toward warmer temperatures over most seasons. The distribution of summer maximum temperatures has become more peaked due to a decrease in cooler maximum temperatures, while the warmest maximum temperatures show little change. Similarly, minimum temperatures have exhibited distributional shifts, throughout consecutive time periods since the late 1800s, toward warmer temperatures. Two-tailed KolmogorovSmirnov tests that showed significant distributional changes were present between consecutive time periods for temperature and precipitation.

Trends in the 27 climate indices over the period 1893 2005 and the two subperiods 1893-1950 and 1951-2005 are shown in Table 4. There is a general increase in the number of positive trends associated with warmer temperature indices, while cooler temperature indices show decreases. Trends and percentiles of the indices for unadjusted temperatures are also given in Table 4 for comparative purposes. In general, the warm temperature indices show stronger warming trends and higher percentages of significant trends associated with the warming trends. Larger decreases in cold temperature indices, such as frost days, are also apparent in the adjusted temperature dataset.

For the 113-yr period, there are statistically significant trends $(95 \%)$ for most stations in all temperature indices that indicate warming, with the exception of the indices associated with warm minimum temperatures (tropical nights and highest minimum temperature). More than half of the stations in the northeastern United States exhibit a significant decreasing trend in all colder minimum and maximum temperature indices, indicating that indices related to cooling have decreased. Precipitation trends show fewer significant trends over the three time periods.

Temperature percentiles and indices show a predominant warming trend from 1893. Average trends in percentiles of running 5-yr July and January temperatures, over the periods 1893-1950 and 1951-2005, are shown in Fig. 7. Both July and January temperature percentiles 


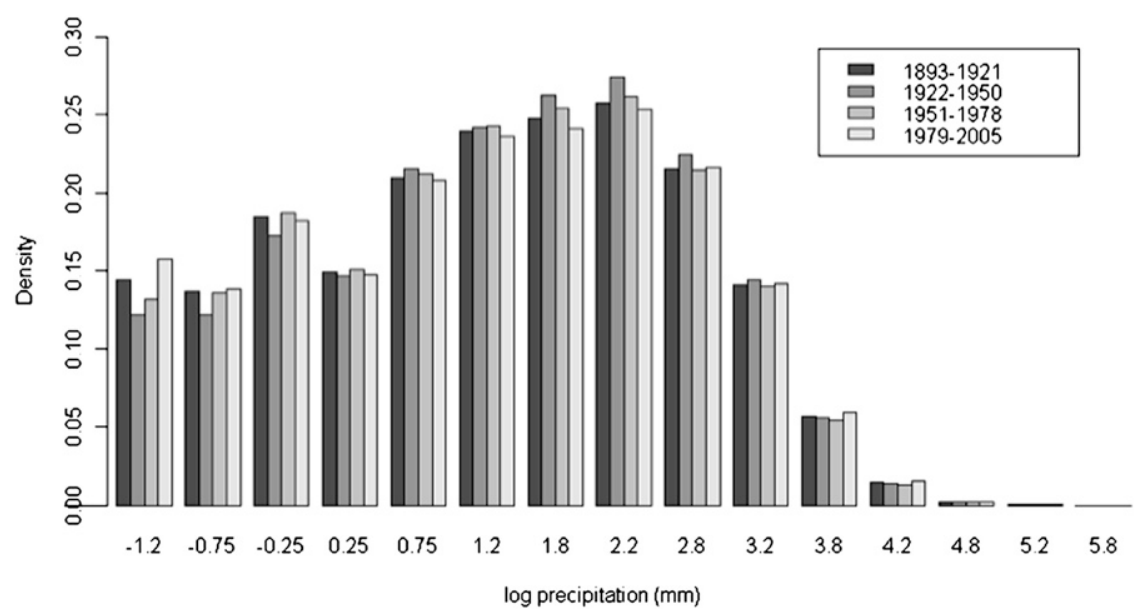

FIG. 4. Temporal change in the density distribution histogram of daily wet-day precipitation amounts for northeastern U.S. stations from 1893 to 2005.

show increasing trends with one exception: the consistent small negative trend in July maximum temperature percentiles since 1950 . The January maximum temperature percentiles indicate changes in the shape of the distribution for 1951-2005 that are consistent with the changes in winter maximum temperatures shown in Fig. 6.

Maximum temperature indices during the first subperiod (1893-1950) show significant decreases (increases) in the cooler (warmer) temperature indices, as seen in the increase in summer days (SU25) shown in Figs. 8a and 9a. These indices have significant trends at between $58 \%$ and $70 \%$ of stations, except for the highest maximum temperatures (TXx). Warmer minimum temperature indices show mixed trends with the only pattern in significant trends being for warm nights (TN90P, Fig. 10a), where increases are noted at coastal stations while inland
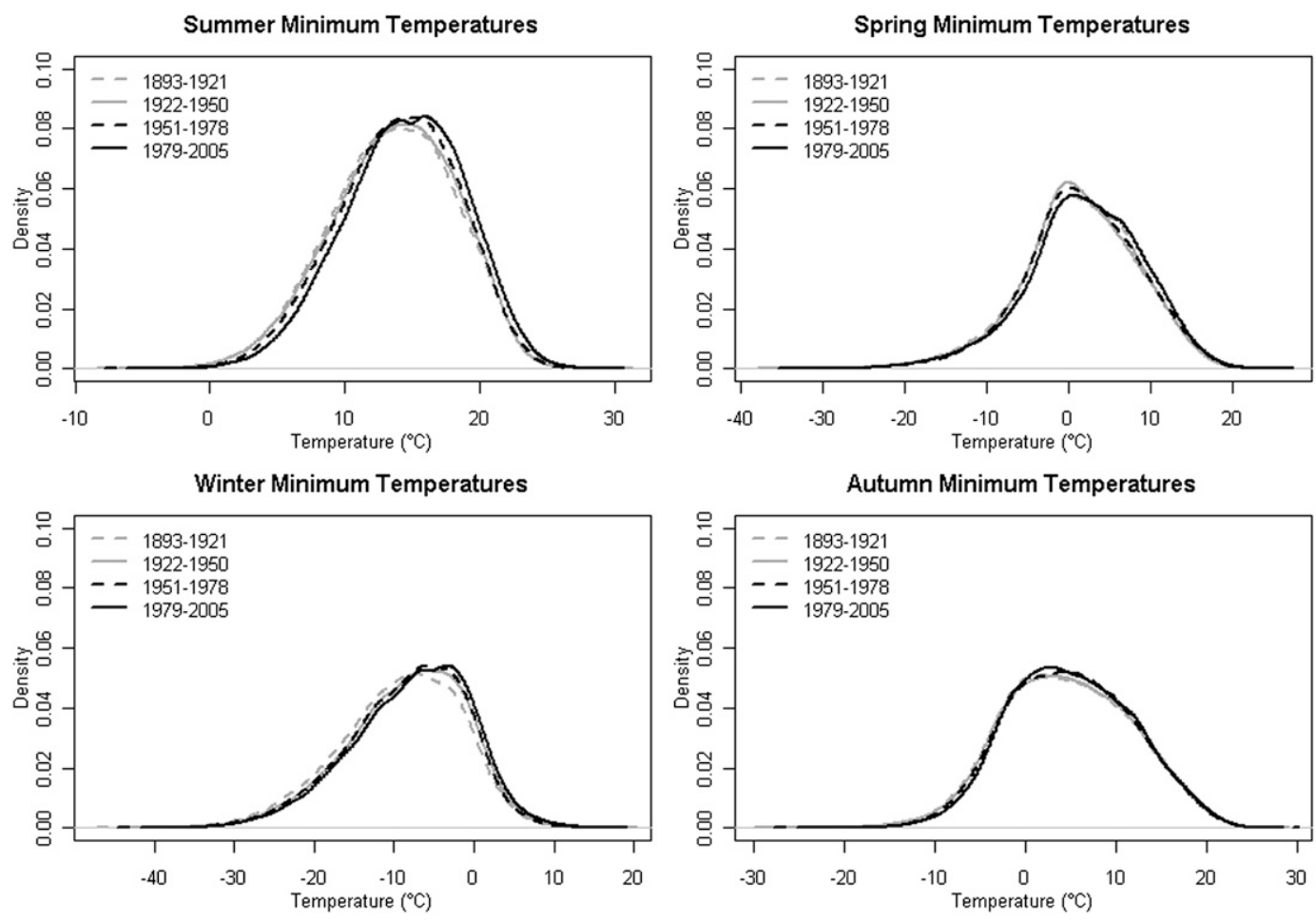

FIG. 5. Temporal change in density distribution plots of summer, spring, winter, and autumn minimum temperatures for northeastern U.S. stations. 
Summer Maximum Temperatures

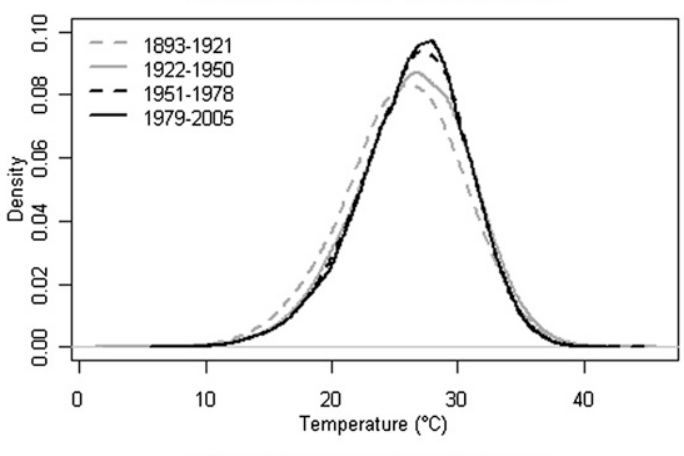

Winter Maximum Temperatures

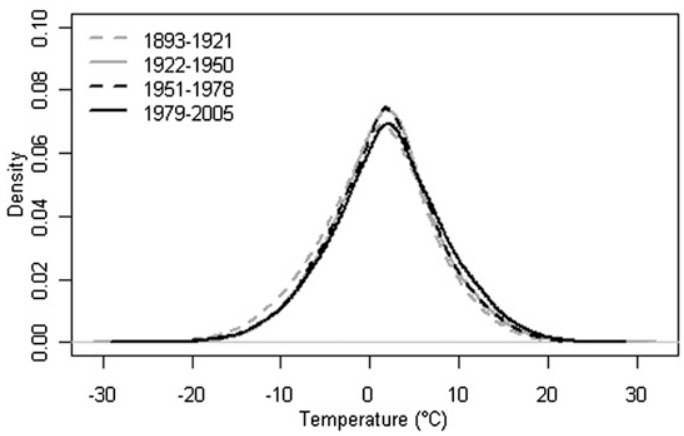

Spring Maximum Temperatures

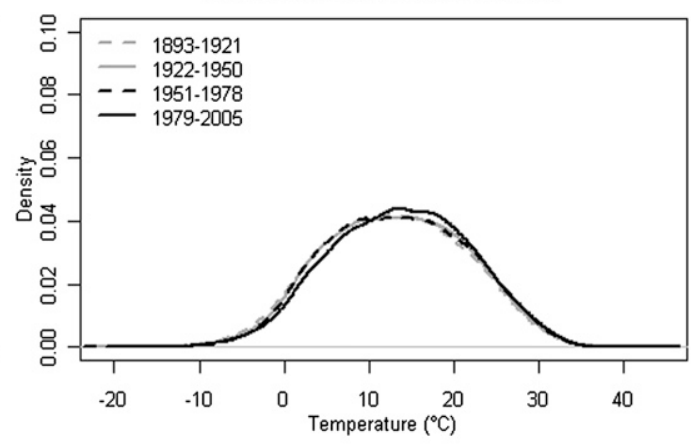

Autumn Maximum Temperatures

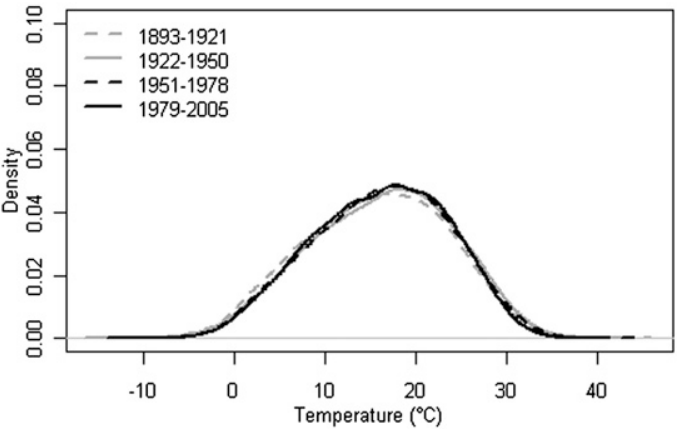

FIG. 6. Temporal change in density distribution plots of summer, spring, winter, and autumn maximum temperatures for northeastern U.S. stations.

stations show decreases. This dichotomy between inland and coastal stations is also present for the colder minimum temperature indices; however, the opposite trends are displayed with decreasing coastal trends and increasing trends inland (Fig. 10c). Over the period 19512005 the strongest trends in temperature indices are associated with warming minimum temperatures and, especially, colder minimum temperatures at coastal stations (Fig. 10d). Frost days decreased in the northeastern United States (Fig. 9a) at a rate of 2.1 days decade $^{-1}$, and the frequency of cold nights exhibits decreasing trends at $65 \%$ of stations. Little significant change is seen in the three colder maximum temperature indices. However, the warmer maximum temperature indices have increased on the coast and decreased inland, as shown in Fig. 10b.

Extended periods of heat or cold also show decreased incidence over the period 1893-2005 with station trends ranging from -0.4 to 1.4 and -0.2 to -2.8 days per decade, respectively. The decreasing frequency of cold spells (CSDI) is apparent at coastal sites over the first subperiod and throughout the Northeast over the second (Figs. 8e and 8f) with 19 stations showing a significant decrease in cold spells since 1893. Some significant changes in warm spells (WSDI)] are seen at inland stations where trends increased initially, then decreased after 1951. The decrease in cold spells and warm spells that has occurred after 1951 contradicts the results obtained by Alexander et al. (2006), who found strong increases in the Northeast. These differences could be attributable to differences in quality control/homogeneity adjustments and the coarse resolution of the gridded data used by Alexander et al. (2006).

The change in diurnal temperature range (DTR) since 1893 shows a similar number of stations with significant increasing trends during the earlier time period and decreasing trends over the later period, with no overall change over the 113-yr record. Figure $9 \mathrm{~b}$ shows an increase in the DTR until a peak of $12^{\circ} \mathrm{C}$ occurred in the early 1940s, followed by a sharp decrease from the 1950s to the 1960s before plateauing over the last $30 \mathrm{yr}$. These changes in DTR are consistent with global DTR trends that occurred between 1950 and 2005 (Vose et al. 2005). The growing season lengthened by 1.5 days decade ${ }^{-1}$ on average since 1893 , with $60 \%$ of stations showing a significant increasing trend. Increases in the average GSL (Fig. 9b) show a consistent increase in GSL over the period of record, although station trends range from -0.9 to 50 days decade ${ }^{-1}$. During the first subperiod the strongest increase in GSL is seen in coastal areas of the U.S. Northeast, whereas after 1950 increases are widespread, 
TABLE 4. Average trends (per year, as listed in Table 3) of the 27 climate indices for the 40 northeastern U.S. stations, and their associated percentages of significant $(95 \%)$ positive $(+)$ and negative $(-)$ trends. The italicized numbers indicate the trends and percentages of the unadjusted temperatures.

\begin{tabular}{|c|c|c|c|c|c|c|c|c|c|}
\hline Index & 1893-2005 trend & $+\%$ & $-\%$ & $1893-1950$ trend & $+\%$ & $-\%$ & 1951-2005 trend & $+\%$ & $-\%$ \\
\hline SU25 & 0.050 .07 & 4350 & 320 & 0.30 & 63 & 3 & -0.03 & 18 & 23 \\
\hline ID0 & $-0.04-0.10$ & 53 & 4065 & -0.20 & 0 & 65 & -0.03 & 3 & 5 \\
\hline TR20 & 0.010 .01 & 1533 & 2020 & 0.01 & 13 & 15 & 0.05 & 35 & 8 \\
\hline FD0 & $-0.01-0.13$ & 2510 & 3568 & -0.05 & 13 & 23 & -0.21 & 10 & 58 \\
\hline TXx & $-0.01-0.01$ & 1010 & 4333 & 0.01 & 20 & 5 & 0.00 & 10 & 18 \\
\hline TXn & 0.010 .01 & 4350 & 33 & 0.07 & 70 & 0 & 0.00 & 5 & 3 \\
\hline $\mathrm{TNx}$ & 0.000 .00 & 1325 & 2820 & 0.00 & 10 & 15 & 0.02 & 43 & 5 \\
\hline $\mathrm{TNn}$ & 0.010 .03 & 4560 & 53 & 0.03 & 23 & 3 & 0.03 & 23 & 3 \\
\hline TX90P & 0.010 .01 & 3340 & 513 & 0.08 & 58 & 3 & 0.01 & 13 & 28 \\
\hline TX10P & $-0.03-0.05$ & 88 & 4368 & -0.12 & 0 & 68 & -0.01 & 15 & 20 \\
\hline TN90P & 0.000 .00 & 3353 & 1815 & 0.01 & 35 & 13 & 0.05 & 48 & 3 \\
\hline TN10P & $-0.02-0.06$ & 2013 & 4065 & -0.04 & 15 & 33 & -0.08 & 10 & 65 \\
\hline GSL & 0.150 .10 & 3860 & 30 & 0.22 & 20 & 0 & 0.23 & 30 & 0 \\
\hline DTR & 0.000 .00 & 4040 & 2028 & 0.02 & 55 & 8 & -0.01 & 18 & 48 \\
\hline WSDI & $-0.01-0.02$ & 55 & 2018 & 0.04 & 20 & 0 & -0.03 & 3 & 18 \\
\hline CSDI & $-0.01-0.04$ & 33 & 2848 & -0.04 & 0 & 15 & -0.04 & 0 & 23 \\
\hline RX1day & 0.06 & 15 & 0 & -0.03 & 5 & 3 & 0.17 & 8 & 0 \\
\hline RX5day & 0.09 & 15 & 0 & 0.08 & 10 & 3 & 0.20 & 13 & 0 \\
\hline $\mathrm{R} 10 \mathrm{~mm}$ & 0.02 & 33 & 8 & -0.03 & 0 & 18 & 0.06 & 20 & 0 \\
\hline $\mathrm{R} 20 \mathrm{~mm}$ & 0.01 & 20 & 3 & -0.03 & 3 & 20 & 0.04 & 23 & 0 \\
\hline $\mathrm{R} 25 \mathrm{~mm}$ & 0.01 & 13 & 3 & -0.03 & 0 & 30 & 0.03 & 15 & 0 \\
\hline $\mathrm{R} 95 \mathrm{p}$ & 0.35 & 25 & 3 & -0.64 & 5 & 10 & 1.20 & 28 & 0 \\
\hline R99p & 0.12 & 13 & 3 & -0.22 & 3 & 3 & 0.56 & 8 & 0 \\
\hline CDD & -0.02 & 0 & 28 & -0.01 & 0 & 5 & -0.01 & 0 & 3 \\
\hline CWD & 0.01 & 35 & 3 & 0.01 & 15 & 0 & 0.00 & 15 & 3 \\
\hline SDII & 0.00 & 25 & 28 & -0.02 & 5 & 40 & 0.01 & 33 & 3 \\
\hline PRCPTOT & 0.80 & 45 & 0 & -0.51 & 3 & 13 & 1.87 & 25 & 0 \\
\hline
\end{tabular}

the exception being in the north where little significant change occurred (Figs. 8c and 8d).

A less coherent response was observed in precipitation indices with stations showing both significant increasing and decreasing trends. However, there is some evidence of an increasing trend in precipitation events, with stations showing more frequent $>10$-mm heavy precipitation days, consecutive wet days (CWD), and annual wetday precipitation. Consecutive dry days (CDD) is the only precipitation index that shows a number of stations $(28 \%)$ with significant negative trends that contribute to an average decrease of 0.2 days decade $^{-1}$ from 1893 to 2005 (Fig. 9c), although the two subperiods exhibit little significant change. Conversely, there are increasing trends of only $0-0.1$ days decade ${ }^{-1}$ in the numbers of CWD over all three time periods.

All three threshold precipitation indices of heavy precipitation days (R10, R20, and R25) show a small number
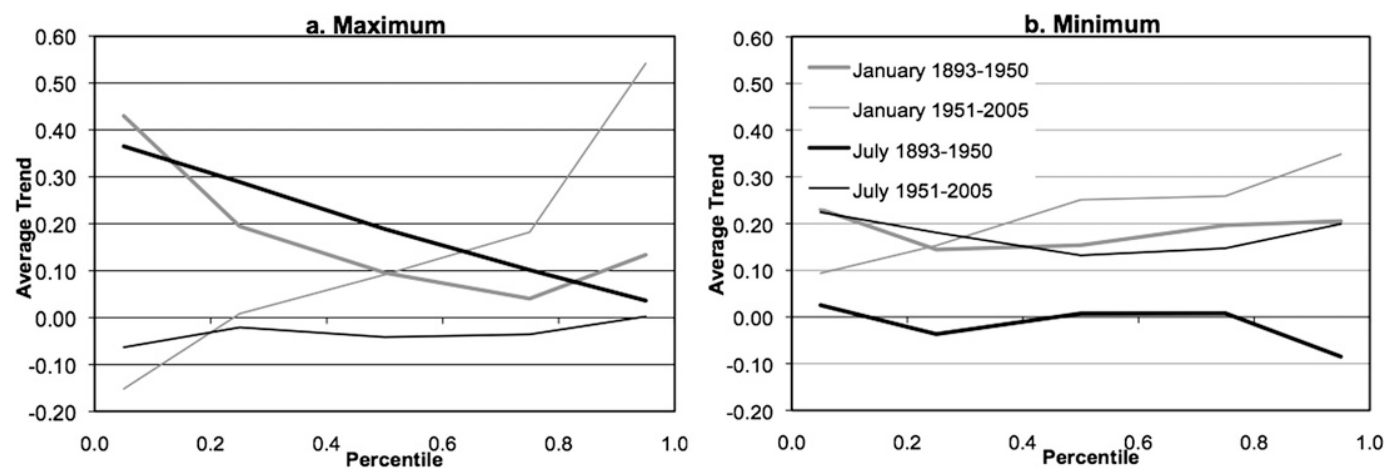

FIG. 7. Average July and January trends from the 40 stations of (a) maximum and (b) minimum temperatures percentiles for running 5-yr periods between 1893 and 1950 and between 1951 and 2005. 
a. SU25: $1893-1950$
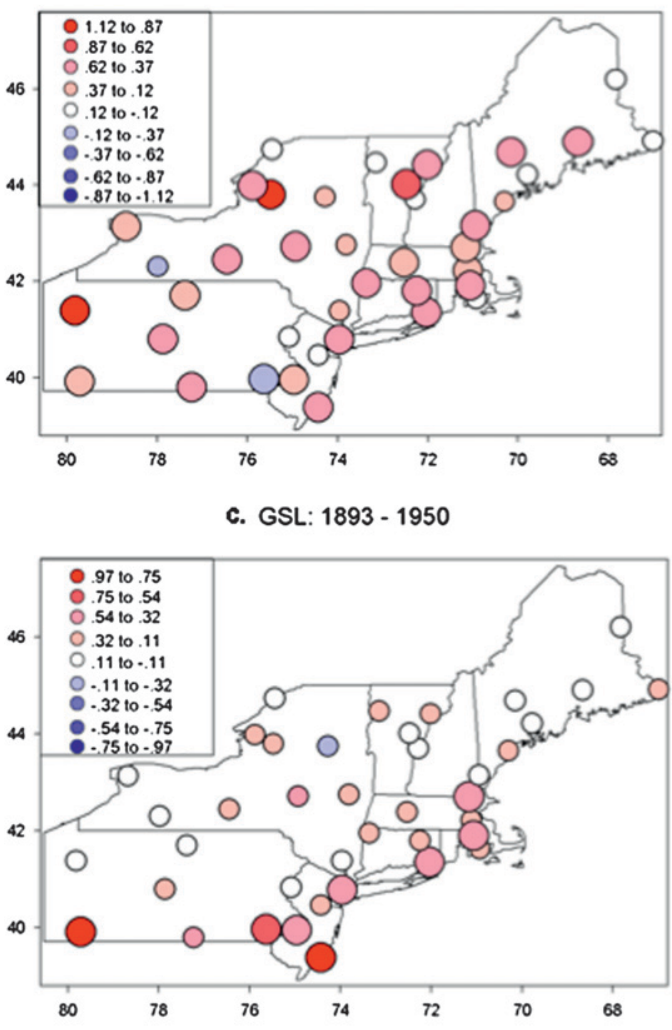

e. CSDI: 1893 - 1950

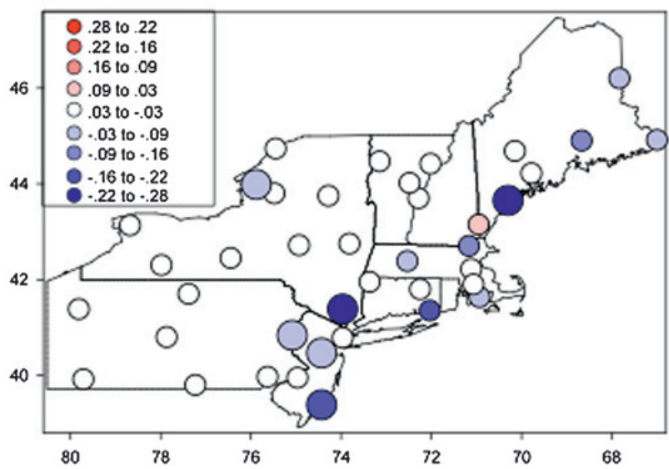

b. SU25: 1951-2005
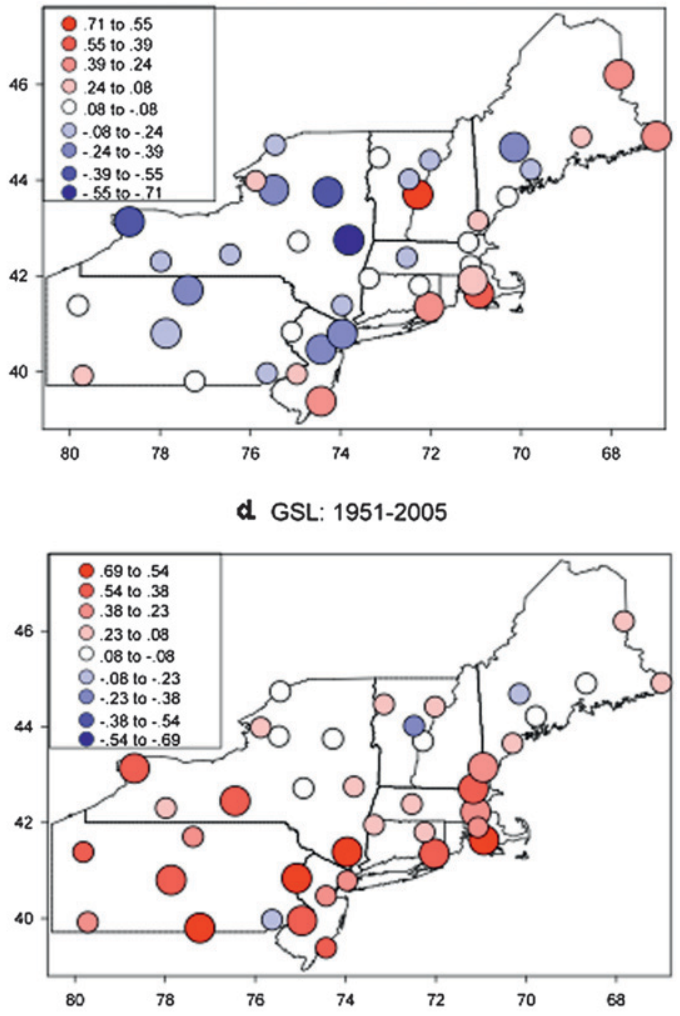

f. CSDI: $1951-2005$

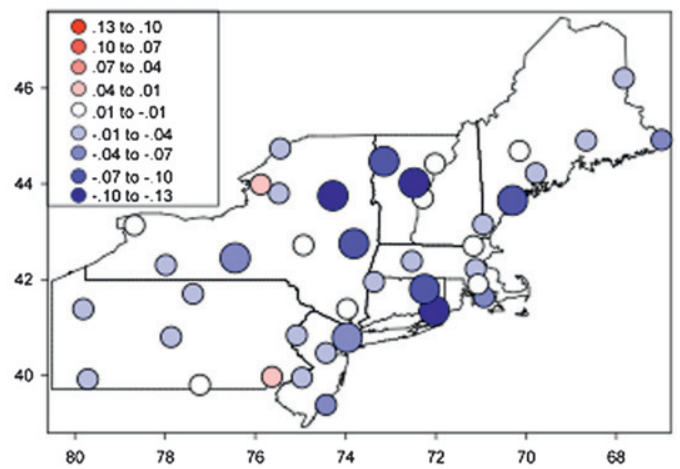

FIG. 8. Trends in the annual temperature indices for summer days (a) SU25: 1893-1950 and (b) SU25: 1951-2005, (c) GSL: 1893-1950 and (d) GSL: 1951-2005, and (e) CSDI: 1893-1950 and (f) CSDI: 1951-2005. Statistically significant trends at $95 \%$ are shown by the large circles. See Table 3 for the units of each measure.

of stations with significant decreasing trends before 1950 , especially for rainfall events over $25 \mathrm{~mm}(\mathrm{R} 25 \mathrm{~mm})$ at coastal sites (Fig. 11a). These three threshold indices display small numbers of significant increasing trends after 1950 (Fig. 11b), with the overall trend since 1893 being positive. Since 1870, total precipitation (PRCPTOT) increased $9 \mathrm{~mm}$ decade $^{-1}$ (Fig. 9c), with almost a third of the stations exhibiting a significant increasing trend. Changes in total precipitation show the same trends as noted for heavy precipitation days before and after 1950, with almost half the stations in the Northeast showing significant increases that amount to $8 \mathrm{~mm} \mathrm{decade}^{-1}$. Small increasing trends in total precipitation have occurred in Maine since 1951 but with no significant trends. The simple daily intensity index (SDII) also decreases in the first subperiod but increases in the last, and trends range between -0.4 and $0.3 \mathrm{~mm}$ day $^{-1}$ decade $^{-1}$. Wet-day indices (R95p and R99p) exhibit some significant but many 

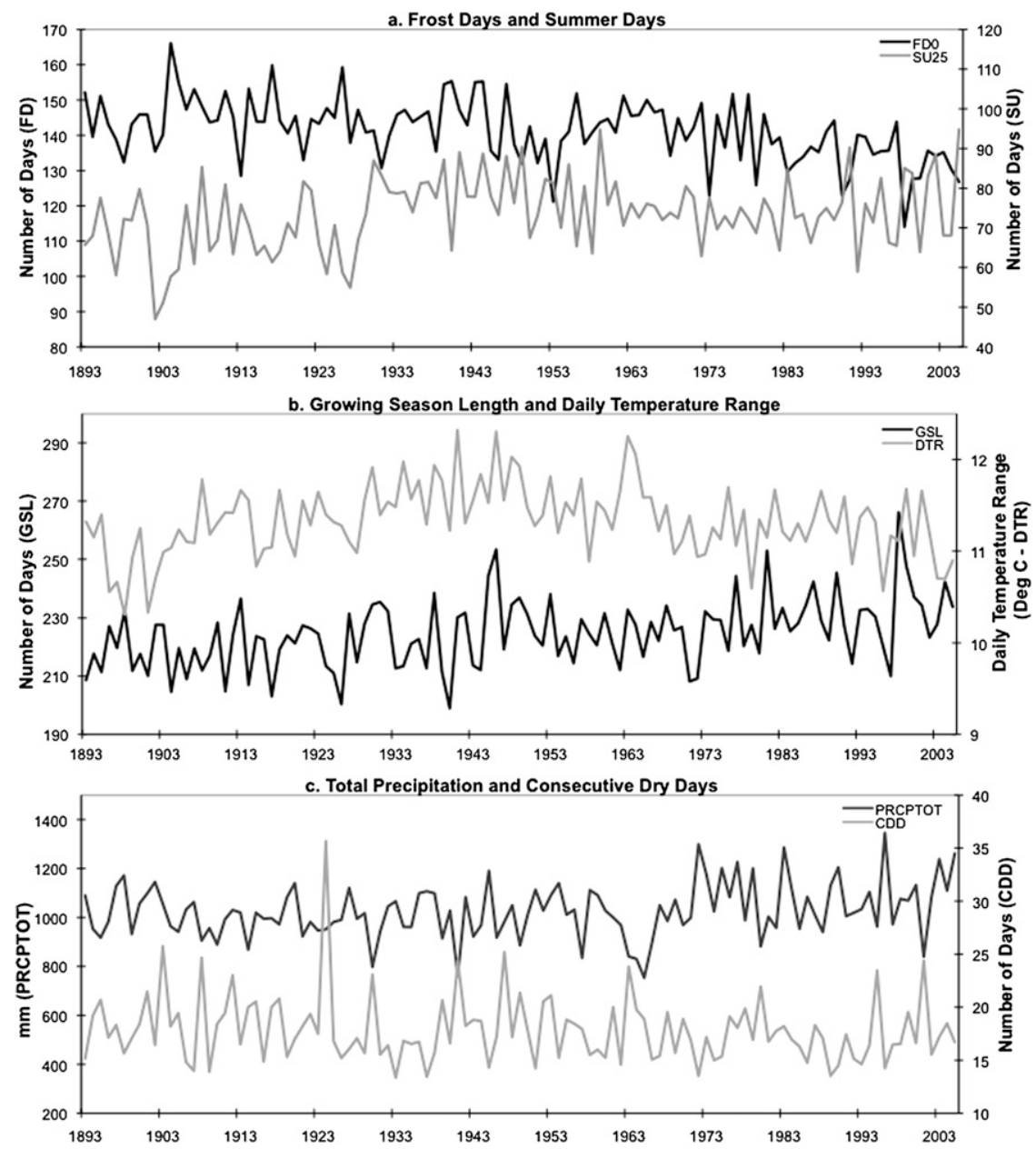

FIG. 9. Indices from 1893 to 2005 for (a) frost days (FD0) and summer days (SU25); (b) growing season length (GSL) and daily temperature range (DTR); (c) total precipitation (PRCPTOT) and consecutive dry days (CDD).

nonsignificant increasing trends at most stations during the period 1951-2005 (Figs. 11c-11f). Few significant trends in wet-day indices were observed during the earlier subperiod, contributing to an overall decreasing trend over the period of record (see Figs. 11e and 11f). The increase in 1-day (RX1day) and 5-day maximum precipitation (RX5day) both show significance but at less than 16\% of stations over the three time periods investigated, with a nonsignificant increasing trend noted at most stations since 1950 (not shown).

The dataset compiled from 12 temperature and 17 precipitation stations that date back to the 1870 s provided 23 more years of historical climate data in the Northeast. Table 5 shows the average trends and percentage of stations with a significant (at 95\%) positive and negative trend. The temperature trends show similar trends to those observed in the 1893-2005 dataset, with warming indicated in all indices. However, the number of stations with significant trends is much higher, especially for the absolute minimum and threshold indices of the maximum and minimum temperatures, where $92 \%$ of stations show significant warming. Precipitation indices from 1870 to 2005 also show increasing trends similar to those observed since 1893, but the percentage of stations showing trends associated with increased rainfall is generally higher.

\section{Discussion}

Similarities between the 1893-2005 and 1870-2005 indices provide evidence of a consistent change in the northeastern U.S. climate toward warmer, wetter conditions. The changes in Northeast temperature indices are much more widespread than those reported by Griffiths and Bradley, which we attribute to the unadjusted dataset analyzed in that study, the different time periods investigated (1926-60, 1961-2000, and 1926-2000), and the 
a TN90P: $1893-1950$

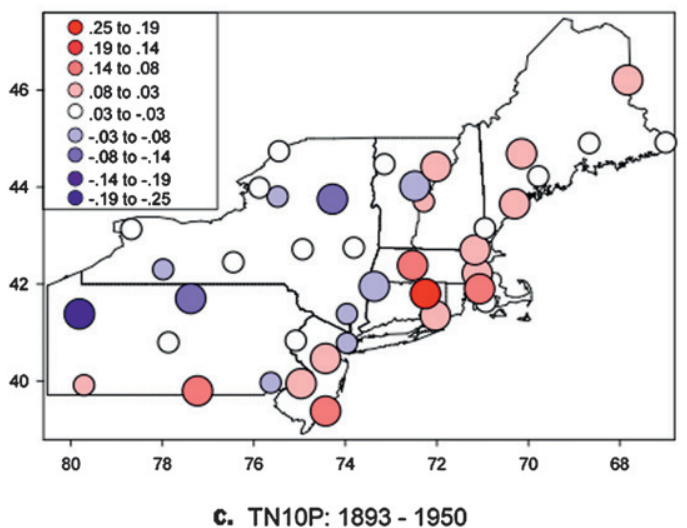

c. TN10P: $1893-1950$

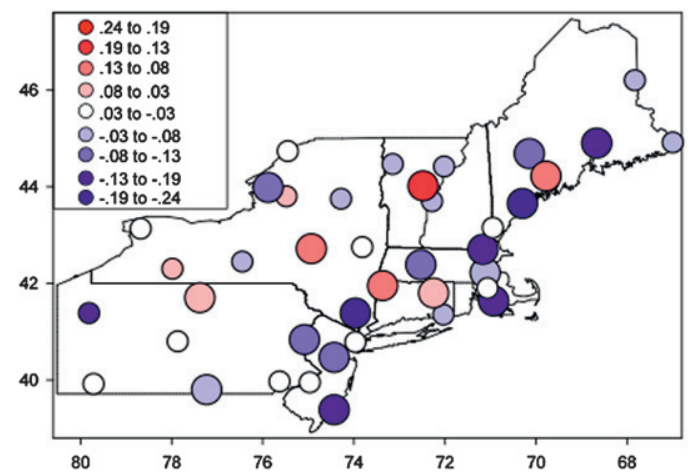

b. TN9OP: $1951-2005$

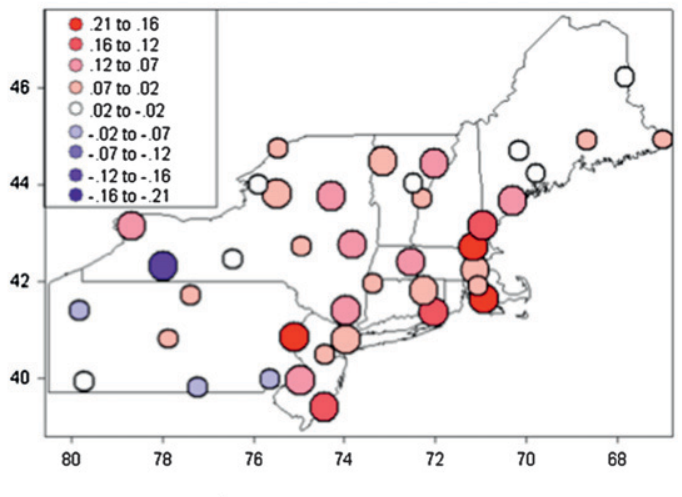

d. TN10P: $1951-2005$

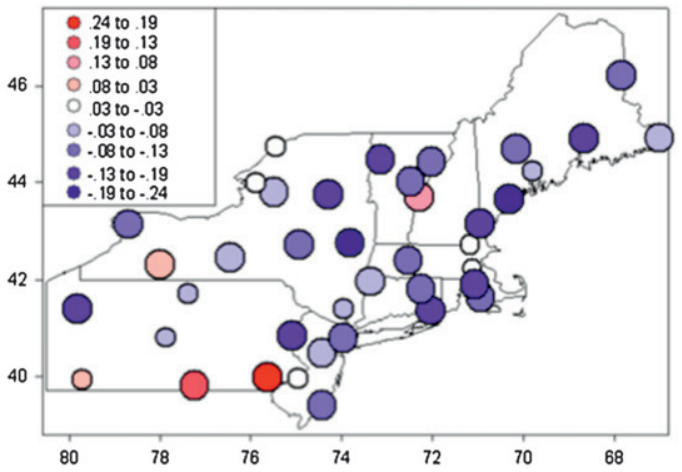

FIG. 10. Trends in the annual temperature indices over the time period specified for cold nights (a) TN90P: 18931950 and (b) TN90P: 1951-2005 and warm nights (c) TN10P: 1893-1950 and (d) TN10P: 1951-2005. Statistically significant trends at $95 \%$ are shown by the large circles. See Table 3 for the units of each measure.

more geographically limited distribution of stations included in their analysis. Regionally coherent increases of maximum temperature indices in the earlier part of the twentieth century are influenced by the increase in maximum temperature indices during the warm period of the 1930s and 1950s. This warm period is associated with drought years and has been noted in others studies (DeGaetano and Allen 2002; Easterling et al. 2000). Increasing minimum temperatures apparent in the secondhalf of the century are well documented in other studies (Frich et al. 2002; Alexander et al. 2006; Peterson et al. 2008).

Disproportionate changes in maximum and minimum temperatures since 1893 have driven the trend in DTR, which shows a slight negative trend overall. Long-term fluctuations in DTR have occurred in the United States, and these fluctuations have resulted in contradictory trends depending on the time period selected (Trenberth et al. 2007). Atmospheric circulation and cloud cover changes have been shown to contribute to changes in DTR and temperatures in the Northeast (Wettstein and Mearns 2002; Durre and Wallace 2001; Trenberth et al. 2007).
While changes in maximum and minimum temperatures have affected DTR, Alexander et al. (2006) noted that many studies show asymmetrical changes in temperature distributions of cold and warm extremes. In another global land study, Caesar et al. (2006) found some regions (including the United States) displayed asymmetric maximum and minimum temperature changes throughout the year, and therefore distributional changes could not be inferred from changes in the mean. However, Peterson et al. (2008) found normalized annual temperature extremes showed a similar magnitude of change in North America. Temperatures in the Northeast indicate asymmetrical change has occurred owing to the colder tails, the temperature distributions warming at a faster rate than the warmer tails, and the changes in the seasonal temperature distributions, seen in Figs. 5 and 6, contributing to these changes. The pattern of warming in the northeastern United States is consistent with the predominant trends in temperatures over the last 100 years or more in other locations, which shows that there is a greater increase in minimum temperatures than in maximum temperatures both regionally and globally (Moberg and Jones 2005; Brunet et al. 2007; Alexander et al. 2006). 
a R25mm: $1893-1950$
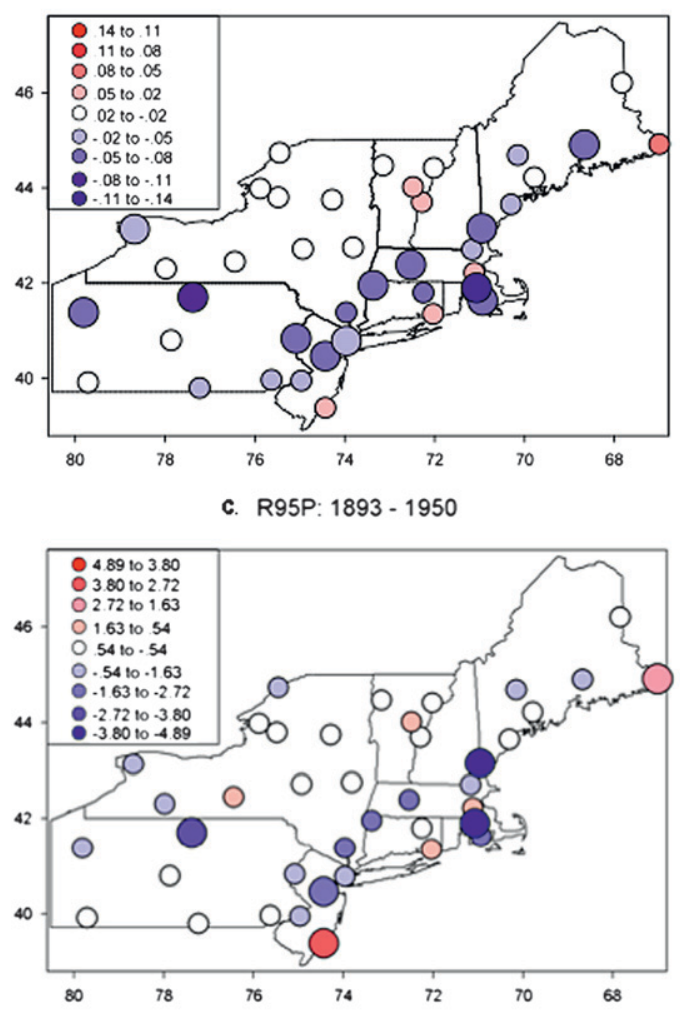

e. R99P: $1893 \cdot 1950$

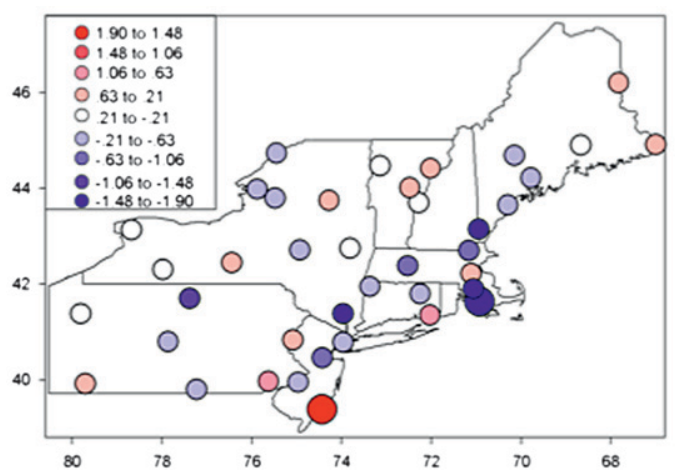

b. R25mm: $1951-2005$

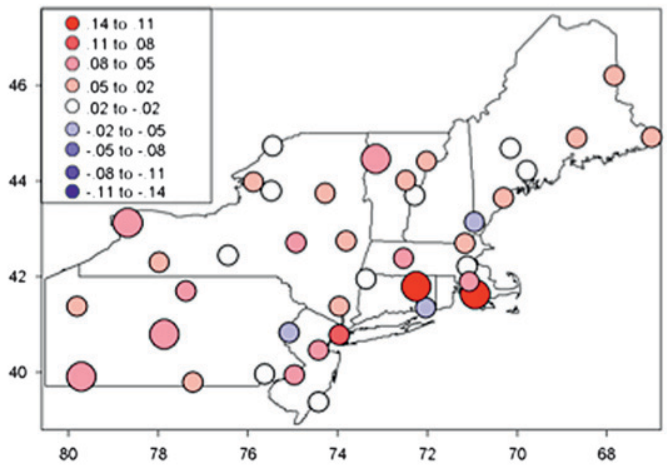

d R95P: 1951-2005

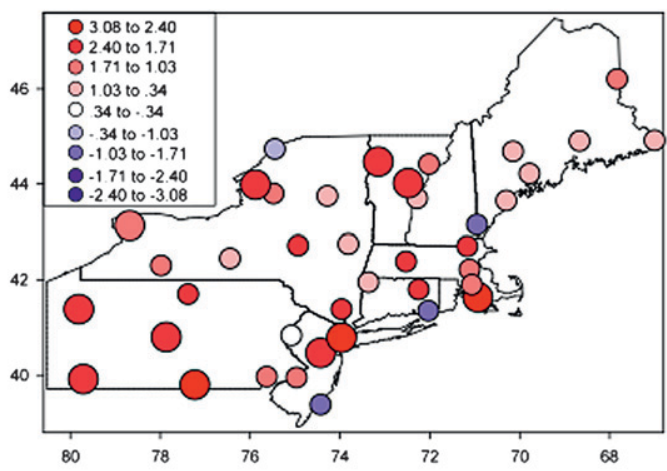

f. R99P: 1951-2005

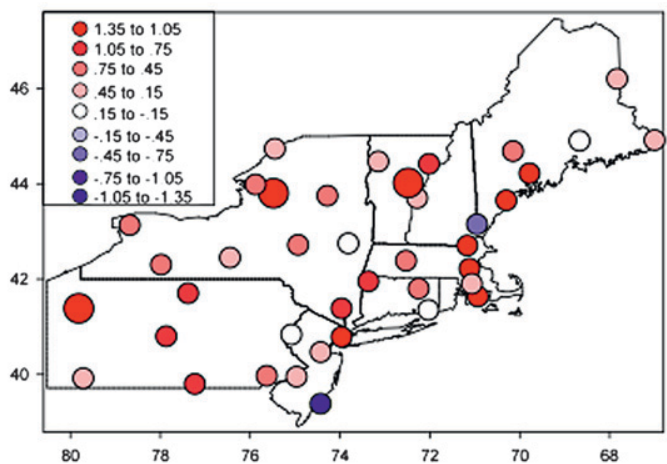

FIG. 11. Trends in the annual precipitation indices over the time period specified for days with over 25-mm precipitation (a) R25mm: 1893-1950 and (b) R25mm: 1951-2005, very wet days (c) R95p: 1893-1950 and (d) R95P: 1951-2005, and extremely wet days (e) R99p: 1893-1950 and (f) R99P: 1951-2005. Statistically significant trends at $95 \%$ are shown by the large circles. See Table 3 for the units of each measure.

Most previous studies of long-term data are based on data that have not been fully homogenized over the longer time period and thus show spatial variability, but nevertheless similar trends dominate all studies.

Strong evidence of warming is also provided by the decreases in frost days; these have been decreasing since 1870, with the strongest decreases over last part of the twentieth century. Conversely, the growing season has been steadily increasing over the last 137 years.
Trends in both frost days and growing season are consistent with those observed in Canada (Vincent and Mekis 2006), in the United States (Kunkel et al. 2004), and reported earlier for the northeast United States, (Griffiths and Bradley 2007). However, a small portion of the northeastern United States that showed a small increase in frost days (1950-2003) in Frich et al. (2002) and Alexander et al. (2006) was not apparent in our analysis. 
TABLE 5. Average trends (per year, as listed in Table 3) of the 27 climate indices for northeastern U.S. stations dating from the 1870 s and their associated percentages of significant positive $(+)$ and negative $(-)$ trends.

\begin{tabular}{lrrr}
\hline \multicolumn{1}{c}{ Index } & $+\%$ & $-\%$ & 1870-2005 trend \\
\hline SU25 & 42 & 17 & 0.03 \\
ID0 & 67 & 17 & 0.04 \\
TR20 & 0 & 92 & -0.08 \\
FD0 & 0 & 92 & -0.22 \\
TXx & 8 & 42 & -0.01 \\
TXn & 92 & 0 & 0.02 \\
TNx & 67 & 0 & 0.01 \\
TNn & 92 & 0 & 0.03 \\
TX90P & 50 & 17 & 0.01 \\
TX10P & 8 & 75 & -0.05 \\
TN90P & 92 & 0 & 0.04 \\
TN10P & 0 & 83 & -0.11 \\
GSL & 92 & 0 & 0.21 \\
DTR & 8 & 58 & -0.01 \\
WSDI & 0 & 83 & -0.11 \\
CSDI & 8 & 25 & -0.01 \\
RX1day & 24 & 6 & 0.03 \\
RX5day & 29 & 0 & 0.09 \\
R10mm & 53 & 12 & 0.02 \\
R20mm & 35 & 12 & 0.01 \\
R25mm & 24 & 18 & 0.01 \\
R95p & 35 & 18 & 0.18 \\
R99p & 12 & 12 & -0.02 \\
CDD & 12 & 35 & -0.02 \\
CWD & 53 & 0 & 0.01 \\
SDII & 47 & 41 & 0.00 \\
PRCPTOT & 35 & 6 & 0.90 \\
\hline
\end{tabular}

A coastal station effect was noted in some of the temperature indices for stronger warming trends over 1893 1950, particularly for maximum temperatures at coastal stations. Keim and Rock (2002) noted stronger warming in coastal zones compared to inland regions in New England and New York. Although urbanization is generally attributed to stronger increases in minimum temperatures, ambient environmental change could be influencing temperatures. Another interesting feature of this analysis is the lack of warming and even some cooling trends found in indices related to the warm tail of the maximum temperature distribution since 1951. DeGaetano and Allen (2002) also saw decreasing trends in warm maximum temperature percentiles for the eastern United States and noted that urban sites displayed larger decreases than rural sites. The decrease in maximum temperatures may be related to precipitation-related changes in soil moisture that have been noted to modulate daily maximum temperatures (Mahmood et al. 2004). Alternatively, complex changes in water vapor feedbacks could be influencing temperature trends.

Wake et al. (2005) noted precipitation increases were greatest in coastal and lake regions. Here, coastal locations show a tendency toward increased total precipitation since 1893; however, the other indices investigated show little spatially coherent evidence of precipitation increases. Increased lake effect precipitation in the western area of the Northeast noted by Griffiths and Bradley (2007) is not seen in the indices. This discrepancy could again be attributable to the different time periods investigated and the more limited spatial coverage of their study and/or the higher quality datasets used in this study.

Increases in total precipitation have occurred during a period when snowfall amounts have been decreasing in the northeastern United States (Burakowski et al. 2008). The sensitivity of the Northeast to changes may reflect the interrelationship between warming temperatures and decreased precipitation as snowfall contributes to increases in rainfall in most areas, except the less climatically marginal northern stations, which has been noted by many studies (Karl et al. 1993; Huntington et al. 2004; Feng and $\mathrm{Hu}$ 2007; Wake et al. 2005). Changes in observation practices since the late 1800s are also likely to distort the long-term trends (Kunkel et al. 2007b). Precipitation totals included a period of time when the estimated snowfall precipitation equivalent was $10 \%$ of the snowfall; however, this "rule of thumb" was only intermittently used throughout the Northeast and throughout the United States (Kunkel et al. 2007a).

Previous studies of temperature and precipitation in the United States have linked climatic variability to a number of large-scale forcing mechanisms, such as the El Niño-Southern Oscillation (ENSO) and the Arctic Oscillation (AO) (Griffiths and Bradley 2007; Leathers et al. 2008). While a comprehensive analysis of the effect of such mechanisms is beyond the scope of this study, an exploratory analysis was performed. Leathers et al. evaluated the association between teleconnection patterns and temperature/precipitation values using significant variables obtained from a stepwise, multiple linear regression (MLR). Six teleconnection patterns were investigated: the Arctic Oscillation (AO), Niño-3.4 SST anomalies (ENSO), the North Atlantic Oscillation (NAO), the Pacific decadal oscillation (PDO), the North Pacific pattern (NP), and the Pacific-North American pattern (PNA) (Table 6). This MLR method was applied using the teleconnection patterns as predictors for each of the 27 indices for two time periods: 1951-2002 and 1900-2002. All indices cover the period 1900-2002, except the PNA which begins in 1950 and therefore excluded from the MLR for the longer time period.

The teleconnection variables showed a similar explanatory power (with an $R$-squared value of up to $22 \%$ ) over the 53-yr period to that obtained by Griffiths and Bradley (2007) and Leathers et al. (2008), who used 
TABLE 6. Sources used to obtain data for AO, Niño-3.4, NAO, PDO, NP index, and the PNA pattern.

\begin{tabular}{|c|c|c|}
\hline Index & Period & Source \\
\hline $\mathrm{AO}$ & 1900-2002 & http://jisao.washington.edu/ao/ \\
\hline Niño-3.4 & $1900-2002$ & $\begin{array}{l}\text { http://www.esrl.noaa.gov/psd/gcos__ } \\
\text { wgsp/Timeseries/Nino34/ }\end{array}$ \\
\hline NAO & 1900-2002 & http://www.cru.uea.ac.uk/cru/data/nao/ \\
\hline PDO & $1900-2002$ & http://jisao.washington.edu/pdo/ \\
\hline NP & $1900-2002$ & $\begin{array}{l}\text { http://www.cgd.ucar.edu/cas/jhurrell/ } \\
\text { indices.html }\end{array}$ \\
\hline PNA & $1950-2002$ & $\begin{array}{l}\text { http://www.cpc.noaa.gov/data/teledoc/ } \\
\text { telecontents.shtml }\end{array}$ \\
\hline
\end{tabular}

similar time periods. However, little explanatory power was obtained for the indices over 103 ears. Superior performance of the teleconnection data over the shorter time scale may be attributable to overfitting or trends in the data, and the strength of these relationships breaks down when using longer datasets. Similarly, the use of MLR to describe the relationship between teleconnection patterns and climate indices may not be linear, as ENSO has also been noted to have a not quite linear relationship with temperature extremes (Nicholls et al. 2005; Kenyon and Hegerl 2008).

Despite the poor explanatory power obtained from the MLR analysis, the PNA showed a weak association with 16 of the temperature indices for the 53-yr period. The PDO and NAO were the only other teleconnection patterns to show coherent associations with temperature indices over the shorter time scale. Over the 103-yr period, there is weak evidence of an association between the AO, PDO, NAO, and NP forcings and the temperature indices. The lack of an ENSO influence could be due to nonlinearity, its connection with other modes of variability such as the AO (Griffiths and Bradley 2007), or a similar but weaker effect on extremes compare to the NP (Kenyon and Hegerl 2008). Precipitation indices did not display any coherent associations with large-scale forcings.

\section{Conclusions}

Using a homogenized long-term daily temperature dataset from the Northeast it is evident that temperatures have warmed since the late 1800s. Early in the record maximum temperatures warmed, followed by a more recent minimum temperature increase, with the coolest minimum and maximum temperatures warming the most. Precipitation data show fewer significant trends than the temperature data, but show that the Northeast is becoming wetter. Large-scale modes of climate variability appear to have little influence on the temperature and precipitation indices in the northeast, but a comprehensive analysis of these interacting effects was not performed. Although beyond the scope of this project, the dataset would benefit from further research into monthly/seasonal trends and also the effect of atmospheric circulation patterns that impact the region. Further research would also benefit from the creation of a homogenous daily precipitation dataset when reliable methods are developed to produce such a time series.

Acknowledgments. We wish to thank the National Climatic Data Center for providing microfiche of early climate observation forms and Paul Della-Marta for providing assistance with the temperature adjustment procedure. Comments and suggestions provided by anonymous reviewers and Art DeGaetano greatly improved this manuscript. This study was funded by the NOAA Grant NA050AR4311106.

\section{REFERENCES}

Alexander, L. V., and Coauthors, 2006: Global observed changes in daily climate extremes of temperature and precipitation. J. Geophys. Res., 111, D05109, doi:10.1029/ 2005JD006290.

Brohan, P., J. J. Kennedy, I. Harris, S. F. B. Tett, and P. D. Jones, 2006: Uncertainty estimates in regional and global observed temperature changes: A new data set from 1850. J. Geophys. Res., 111, D12106, doi:10.1029/2005JD006548.

Brunet, M., and Coauthors, 2007: Temporal and spatial temperature variability and change over Spain during 1850-2005. J. Geophys. Res., 112, D12117, doi:10.1029/2006JD008249.

Burakowski, E. A., C. P. Wake, B. Braswell, and D. P. Brown, 2008: Trends in wintertime climate in the northeastern United States: 1965-2005. J. Geophys. Res., 113, D20114, doi:10.1029/ 2008JD009870.

Cohn, T. A., and H. F. Lins, 2005: Nature's style: Naturally trendy. Geophys. Res. Lett., 32, L23402, doi:10.1029/2005GL024476.

DeGaetano, A. T., and R. J. Allen, 2002: Trends in twentiethcentury temperature extremes across the United States. J. Climate, 15, 3188-3205.

Della-Marta, P. M., and H. Wanner, 2006: A method of homogenizing the extremes and mean of daily temperature measurements. J. Climate, 19, 4179-4197.

—_, M. R. Haylock, J. Luterbacher, and H. Wanner, 2007: Doubled length of western European summer heat waves since 1880. J. Geophys. Res., 112, D15103, doi:10.1029/ 2007JD008510.

Durre, I., and J. M. Wallace, 2001: The warm season dip in the diurnal temperature range over the eastern United States. J. Climate, 14, 354-360.

Easterling, D. R., T. R. Karl, J. H. Lawrimore, and S. A. Del Greco, 1999: United States historical climatology network daily temperature, precipitation, and snow data for 1871-1997. Carbon Dioxide Information Analysis Center, Oak Ridge National Laboratory Rep. ORNL/CDIAC-118, NDP-070, 84 pp. , J. L. Evans, P. Ya. Groisman, T. R. Karl, K. E. Kunkel, and P. Ambenje, 2000: Observed variability and trends in extreme climate events: A brief review. Bull. Amer. Meteor. Soc., 81, $417-425$. 
Feng, S., and Q. Hu, 2007: Changes in winter snowfall/precipitation ratio in the contiguous United States. J. Geophys. Res., 112, D15109, doi:10.1029/2007JD008397.

Frich, P., L. V. Alexander, P. Della-Marta, B. Gleason, M. Haylock, A. M. G. Klein, and T. Peterson, 2002: Observed coherent changes in climatic extremes during the second half of the twentieth century. Climate Res., 19, 193-212.

Griffiths, M. L., and R. S. Bradley, 2007: Variations of twentiethcentury temperature and precipitation extreme indicators in the northeast United States. J. Climate, 20, 5401-5417.

Hansen, J., R. Ruedy, M. Sato, M. Imhoff, W. Lawrence, D. Easterling, T. Peterson, and T. Karl, 2001: A closer look at United States and global surface temperature change. J. Geophys. Res., 106, 23 947-23963.

Horton, E. B., C. K. Folland, and D. E. Parker, 2001: The changing incidence of extremes in worldwide and central England temperatures to the end of the twentieth century. Climatic Change, 50, 267-295.

Huntington, T. G., G. A. Hodgkins, B. D. Keim, and R. W. Dudley, 2004: Changes in the proportion of precipitation occurring as snow in New England (1949-2000). J. Climate, 17, 2626.

Karl, T. R., P. Ya. Groisman, R. W. Knight, and R. R. Heim, 1993: Recent variations of snow cover and snowfall in North America and their relation to precipitation and temperature variations. J. Climate, 6, 1327-1344.

- N. Nicholls, and A. Ghazi, 1999: CLIVAR/GCOS/WMO workshop on indices and indicators for climate extremes: Workshop summary. Climatic Change, 42, 3-7.

Keim, B., and B. Rock, 2002: New England region's changing weather and climate. New England regional assessment of the potential consequences of climate variability and change, USGCRP Rep., 9-18.

Kenyon, J., and G. C. Hegerl, 2008: Influence of modes of climate variability on global temperature extremes. J. Climate, 21, 3872-3889.

Kiktev, D., D. Sexton, L. Alexander, and C. Folland, 2003: Comparison of modeled and observed trends in indices of daily climate extremes. J. Climate, 16, 3560-3571.

Klein Tank, A. M. G., and Coauthors, 2006: Changes in daily temperature and precipitation extremes in central and south Asia. J. Geophys. Res., 111, D16105, doi:10.1029/ 2005JD006316.

_ F. W. Zwiers, and X. Zhang, 2009: Guidelines on analysis of extremes in a changing climate in support of informed decisions for adaptation. Climate Data and Monitoring Rep. WCDMP 72, WMO-TD 1500, 56 pp.

Kunkel, K. E., D. R. Easterling, K. T. Redmond, and K. G. Hubbard, 2004: Temporal trends in frost-free season in the United States: 1895-2000. Geophys. Res. Lett., 31, L03201, doi:10.1029/2003GL018624

—- K. G. Hubbard, D. Easterling, D. Robinson, and K. T. Redmond, 2007a: Trend identification of twentieth-century snowfall: The challenges. J. Atmos. Oceanic Technol., 24, 64-73.

_ , T. R. Karl, and D. R. Easterling, 2007b: A Monte Carlo assessment of uncertainties in heavy precipitation frequency variations. J. Hydrometeor., 8, 1152-1160.

Leathers, D. J., M. L. Malin, D. B. Kluver, G. R. Henderson, and T. A. Bogart, 2008: Hydroclimatic variability across the Susquehanna River Basin, USA, since the 17th century. Int. J. Climatol., 28, 1615-1626.
Mahmood, R., K. G. Hubbard, and C. Carlson, 2004: Modification of growing-season surface temperature records in the northern Great Plains. Int. J. Climatol., 24, 311-327.

Manton, M. J., and Coauthors, 2001: Trends in extreme daily rainfall and temperature in Southeast Asia and the South Pacific: 1961-1998. Int. J. Climatol., 21, 269-284.

Meehl, G. A., C. Tebaldi, and D. Nychka, 2004: Changes in frost days in simulations of 21st century climate. Climate Dyn., 23, 495-511.

Menne, M. J., C. N. Williams Jr., and R. S. Vose, cited 2006: Longterm daily and monthly climate records from stations across the contiguous United States. [Available online at http:// cdiac.ornl.gov/epubs/ndp/ushcn/ushcn.html.]

Mitchell, T. D., and P. D. Jones, 2005: An improved method of constructing a database of monthly climate observations and associated high-resolution grids. Int. J. Climatol., 25, 693-712.

Moberg, A., and P. D. Jones, 2005: Trends in indices for extremes in daily temperature and precipitation in central and western Europe, 1901-99. Int. J. Climatol., 25, 1149_ 1171.

Nicholls, N., and Coauthors, 2005: The El Niño-Southern Oscillation and daily temperature extremes in east Asia and the west Pacific. Geophys. Res. Lett., 32, L16714, doi:10.1029/ 2005 GL022621.

Peterson, T. C., C. Folland, G. Gruza, W. Hogg, A. Mokssit, and N. Plummer, 2001: Report on the activities of the Working Group on Climate Change Detection and related rapporteurs 1998-2001. World Meteorological Organization Rep. WCDMP47, WMO-TD 1071, 143 pp.

—, X. Zhang, M. Brunet-India, and J. L. Vázquez-Aguirre, 2008: Changes in North American extremes derived from daily weather data. J. Geophys. Res., 113, D07113, doi:10.1029/ 2007JD009453.

Smith, T. M., and R. W. Reynolds, 2005: A global merged land air and sea surface temperature reconstruction based on historical observations (1880-1997). J. Climate, 18, 2021-2036.

Trenberth, K. E., and Coauthors, 2007: Observations: Surface and atmospheric climate change. Climate Change 2007: The Physical Science Basis, S. Solomon et al., Eds., Cambridge University Press, 235-336.

Trewin, B. C., 2001: Extreme temperature events in Australia. $\mathrm{Ph} . \mathrm{D}$. thesis, University of Melbourne, $239 \mathrm{pp}$.

Vincent, L., and É. Mekis, 2006: Changes in daily and extreme temperature and precipitation indices for Canada over the twentieth century. Atmos.-Ocean, 44, 177-193.

Vose, R. S., R. L. Schmoyer, P. M. Steurer, T. C. Peterson, R. Heim, T. R. Karl, and J. K. Eischeid, 1992: The Global Historical Climatology Network: Long-term monthly temperature, precipitation, sea-level pressure, and station pressure data. Oak Ridge National Laboratory Rep. ORNL/ CDIAC-53, 25 pp. [Available from Carbon Dioxide Information Analysis Center, Oak Ridge National Laboratory, Oak Ridge, TN 37831-6335.]

_ D. R. Easterling, and B. Gleason, 2005: Maximum and minimum temperature trends for the globe: An update through 2004. Geophys. Res. Lett., 32, L23822, doi:10.1029/2005GL024379.

Wake, C. P., and Coauthors, cited 2005: Indicators of climate change in the Northeast 2005. [Available online at http://www. cleanair-coolplanet.org/information/pdf/indicators.pdf.]

Wang, X. L., and Y. Feng, cited 2004: RHTest user manual. [Available online at http://cccma.seos.uvic.ca/ETCCDMI/ software.shtml.] 
Wettstein, J. J., and L. O. Mearns, 2002: Simulating the influence of the North Atlantic-Arctic Oscillation on mean, variance, and extremes of temperature in the northeastern United States and Canada. J. Climate, 15, 3586-3600.

Wilks, D. S., 1997: Resampling hypothesis tests for autocorrelated fields. J. Climate, 10, 65-82.

Williams, C. N., Jr., M. J. Menne, R. S. Vose, and D. R. Easterling, cited 2006: United States Historical Climatology Network daily temperature, precipitation, and snow data. ORNL/ CDIAC-118, NDP-070, Carbon Dioxide Information Analysis Center, Oak Ridge National Laboratory. [Available online at http://cdiac.ornl.gov/epubs/ndp/ushcn/ndp070 html.]

Zhang, X., and F. Yang, cited 2006: RClimDex (1.0) user manual. [Available online at http://cccma.seos.uvic.ca/ETCCDI/software. shtml.]

, and Coauthors, 2005: Trends in Middle East climate extreme indices from 1950 to 2003. J. Geophys. Res., 110, D22104, doi:10.1029/2005JD006181.

_ - F. W. Zwiers, and G. C. Hegerl, 2009: The influences of data precision on the calculation of temperature percentile indices. Int. J. Climatol., 29, 321-327. 